Full length article

\title{
Nitric oxide-releasing vascular grafts: A therapeutic strategy to promote angiogenic activity and endothelium regeneration
}

\author{
Fatemeh Kabirian ${ }^{\mathrm{a}, \mathrm{b}, \mathrm{c}}$, Peiman Brouki Milan ${ }^{\mathrm{c}, \mathrm{d}}$, Ali Zamanian ${ }^{\mathrm{a}}$, Ruth Heying ${ }^{\mathrm{b}}$, Masoud Mozafari ${ }^{\mathrm{a}, \mathrm{c}, \mathrm{d}, *}$ \\ a Bioengineering Research Group, Nanotechnology and Advanced Materials Department, Materials and Energy Research Center (MERC), Tehran, Iran \\ ${ }^{\mathrm{b}}$ Cardiovascular Developmental Biology, Department of Cardiovascular Sciences, KU Leuven, Leuven, Belgium \\ ${ }^{\mathrm{C}}$ Cellular and Molecular Research Center, Iran University of Medical Sciences, Tehran, Iran \\ ${ }^{\mathrm{d}}$ Department of Tissue Engineering E Regenerative Medicine, Faculty of Advanced Technologies in Medicine, Iran University of Medical Sciences (IUMS), Tehran, Iran
}

\section{A R T I C L E I N F O}

\section{Article history:}

Received 12 February 2019

Received in revised form 26 April 2019

Accepted 1 May 2019

Available online 3 May 2019

\section{Keywords:}

Vascular grafts

Nitric oxide

Biomaterials

3d-printing

Tissue engineering

Endothelium regeneration

Angiogenesis

\begin{abstract}
A B S T R A C T
Small-diameter vascular grafts (SDVGs) are associated with a high incidence of failure due to infection and obstruction. Although several vascular grafts are commercially available, specific anatomical differences of defect sites require patient-based design and fabrication. Design and fabrication of such customtailored grafts are possible with 3d-printing technology. The aim of this study is to develop 3d-printed SDVGs with a nitric oxide (NO)-releasing coating to improve the success rate of implantation. The SDVGs were printed from polylactic acid and coated with blending of $10 \mathrm{wt} \% \mathrm{~S}$-nitroso-N-acetyl-Dpenicillamine into the polymeric substrate consisting of poly (ethylene glycol) and polycaprolactone. Our results show that NO is released in the physiological range $\left(0.5-4 \times 10^{-10} \mathrm{~mol} \cdot \mathrm{cm}^{-2} \cdot \mathrm{min}^{-1}\right)$ for 14 days and NO-releasing coating showed significant antibacterial potential against Gram-positive and Gram-negative strains. It was shown that both NO-releasing and control grafts are biocompatible invitro and in-vivo. Interestingly, the NO-releasing SDVGs dramatically enhanced ECs proliferation and significantly enhanced ECs migration in-vitro compared to control grafts. In addition, the NO-releasing SDVGs showed angiogenic potential in-vivo which can further prove the results of our in-vitro study. These findings are expected to facilitate tissue regeneration and integration of custom-made vascular implants with enhanced clinical success.
\end{abstract}

\section{Statement of significance}

A series of 3d-printed small-diameter vascular grafts (SDVGs, $<6 \mathrm{~mm}$ ) with controlled release of nitric oxide (NO) were prepared to combine the advantages of 3D printing technology and NO-releasing systems. The resulting NO-releasing grafts were promisingly showing sustained NO release in the physiological range over a two weeks period. In addition to the evaluation of endothelial cell migration in-vitro, we implanted for the first time the NO-releasing vascular grafts in a chick chorioallantoic membrane (CAM) to investigate the effect of the prepared grafts on the angiogenesis in-vivo. The fabricated grafts also exhibited bactericidal properties which prevent the formation of a biofilm layer and can thereby enhance the chance of endothelialization on the surface. Taken together, the innovative combination of rapid and highly accurate 3d-printing technology as a patient-specific fabrication method with NO-releasing coating represents a promising approach to develop bactericidal SDVGs with improved endothelialization. (c) 2019 Acta Materialia Inc. Published by Elsevier Ltd. All rights reserved.

\section{Introduction}

The blood-contacting surface of implanted biomaterial is a competitive site for adhesion and colonization of bacteria or

\footnotetext{
* Corresponding author at: Department of Tissue Engineering \& Regenerative Medicine, Faculty of Advanced Technologies in Medicine, Iran University of Medical Sciences (IUMS), Tehran, Iran.

E-mail address: mozafari.masoud@gmail.com (M. Mozafari).
}

attachment of host cells and tissue integration, especially during the first $6 \mathrm{~h}$ of post-implantation known as "decisive period". This competitive process is critical to the success of implants to be integrated into surrounding tissue or failure and loss of implants by the formation of bacterial biofilm which prevents tissue integration [1-3]. Therefore, the development of biomaterials with an engineered surface to promote tissue integration and simultaneously kill bacteria is an emerging field in cardiovascular tissue engineering. 
Among blood-contacting biomaterials, small-diameter $(<6 \mathrm{~mm})$ vascular grafts (SDVGs) are predisposed to a higher failure rate due to stenosis, infection and poor endothelialization [4-8]. Currently, controlled release of antibiotic molecules and silver nanoparticles are the common approaches to create antibacterial surfaces. Despite the significant bactericidal effect of these releasing systems, the consequent undesirable side effects such as development of antibiotic resistance and cytotoxicity are inevitable, respectively [9-12]. Moreover, this type of antibacterial grafts could not promote endothelialization of newly implanted surface. An important postoperative complication is delayed wound healing and tissue regeneration which affects a considerable population of patients such as individuals suffering from vascular disorders or diabetes and elderly patients worldwide [13]. Therefore, it is an important demand to develop biomaterials with an improved endothelialization and accelerated healing process while combating pathogenic bacteria.

The internal layer of blood vessels is covered with a monolayer of endothelial cells (ECs), which are in direct contact with blood flow and continuously releasing nitric oxide (NO) to regulate the vascular homeostasis [14]. NO is a crucial signaling molecule to promote EC migration and proliferation and acts as an antibacterial agent which can circumvent antibiotic resistance $[10,15,16]$.

Since the pre-seeding of artificial grafts with autologous ECs is a time-consuming process and the storage and transportation of the final product would be limited, the new approach of tissue engineering is build up on attraction and adhesion of host cells to the surface of the biomaterial in-vivo [17]. Therefore, accelerated migration and proliferation of cells towards the luminal site of the implanted graft is highly desirable for a successful integration of the implant into surrounding native tissue. The exogenous NO supplementation such as using NO donors is a promising candidate coating to biomimetically modify the surface of blood-contacting biomaterials such as vascular grafts and stents. There are considerable studies that support the benefits and non-cytotoxic effects of NO-releasing surfaces for mammalian cells. For instance, Goudie et al. fabricated Elast-eon E2As films with $10 \mathrm{wt} \%$ S-nitroso-Nacetyl-D-penicillamine (SNAP) and reported zero toxicity of extracts for L-929 mouse fibroblast cells [18,19]. The noncytotoxic nature of NO was also proved for mouse fibroblast cells from silicone rubber tubings releasing liquid-infused NO [20] and NO-releasing polydimethylsiloxane (PDMS) [21].

Furthermore, ECs were shown to be attracted towards biomaterials with NO release. Recently, the NO-catalytic bioactive coating was developed and the results demonstrated an enhancement of HUVEC adhesion, migration and proliferation [16]. In another study, the NO-generating coating for vascular stents was developed and the results showed the enhancement of EC migration and proliferation and promotion of endothelialization [22].

The next generation of implants is needed to be designed and fabricated to fit with various, individual patients vessel geometry obtained by medical imaging such as MRI and CT scan. To achieve this goal, employing the 3d-printing technology could be extremely helpful. This layer by layer technique is able to fabricate reproducible, cost-effective, accurate and complex anatomical geometries for new grafts [23]. Among different techniques of 3d-printing, fused deposition modeling (FDM) is the most popular nozzle based technique which produces objects by extruding thermoplastic filaments like polylactic acid (PLA) [24]. PLA and poly ( $\varepsilon-$ caprolactone) (PCL) are widely used polymers for the fabrication of biodegradable vascular grafts [25], providing appropriate mechanical support and replacing newly regenerated tissue by long-term degradation [26,27].

This study investigated the innovative principle of incorporating 3d-printing technology and a controlled NO release system to develop the next generation of regenerative SDVGs which is characterized by a simple, inexpensive and reproducible method to fabricate patient-based biodegradable and biocompatible SDVGs. We aimed to accelerate the endothelialization and protect the surface from bacterial infection by controlled release of NO. Therefore, the biodegradable polymers were used in this study and the effect of NO-release in physiologic range on ECs proliferation, viability, morphology and migration were investigated. Moreover, the chorioallantoic membrane (CAM) assay was used as an invivo model to investigate the biocompatibility and angiogenesis of fabricated grafts and the bactericidal potential of NO-releasing SDVGs was also evaluated.

\section{Materials and methods}

\subsection{Materials}

$\mathrm{N}$-Acetyl-D-penicillamine (NAP), sodium nitrate, vanadium (III) chloride $\left(\mathrm{VCl}_{3}\right)$, sulfanilamide, $\mathrm{N}$-(1-naphthyl) ethylene diamine dihydrochloride (NEDD), PCL $(\mathrm{Mn}=80,000, \mathrm{Mw} / \mathrm{Mn}<2$ ), BioUltra grade PEG $(\mathrm{Mn}=4000)$, dimethyl sulfoxide (DMSO) and thiazolyl blue tetrazolium were purchased from Sigma-Aldrich (St. Louis, MO). PLA filament $(\mathrm{Mn} \approx 100,000$, white, diameter $1.75 \mathrm{~mm}$ ) was supplied by Shenzhen eSUN Industrial Company (Shenzhen, China). Sulfuric acid $\left(\mathrm{H}_{2} \mathrm{SO}_{4}\right)$, hydrochloric acid $(\mathrm{HCl})$, orthophosphoric acid $\left(\mathrm{H}_{3} \mathrm{PO}_{4}\right)$, methanol, tetrahydrofuran (THF), tryptic soy broth (TSB), Luria broth (LB) and sodium nitrite $\left(\mathrm{NaNO}_{2}\right)$ were obtained from Merck (Darmstadt, Germany). Human umbilical vein endothelial cells (HUVECs, NCBI Code: C554) were obtained from the Cell Bank of the Pasteur Institute (Tehran, Iran). Calcium and magnesium free Dulbecco's phosphate buffered saline (PBS, pH 7.4), Dulbecco's modified Eagle's medium (DMED), fetal bovine serum (FBS) and penicillin/streptomycin were purchased from Gibco (Scotland, UK).

\subsection{Design of CAD model and 3d-printing of SDVGs}

The tubular SDVG was designed using Rhinoceros ${ }^{\circledR}$ CAD software (version 5 SR8, Robert McNeel \& Associates). Height, internal diameter and wall thickness of objects were kept at $10 \mathrm{~mm}, 5 \mathrm{~mm}$ and $0.2 \mathrm{~mm}$, respectively. The CAD model data were saved in STL format and sliced layer by layer with CURA slicing software (Ultimaker BV, Geldermalsen, Netherlands). The G-code was created in CURA and imported into the home-made FDM 3d-printer (optimized in our lab) to create the grafts. The SDVGs were deposited layer by layer on a heated platform by extrusion of PLA filament through a $220^{\circ} \mathrm{C}$ nozzle with $200 \mu \mathrm{m}$ internal diameter. It has been shown that parallel struts represent a more homogeneous structure compared to perpendicular printed struts [28]. Therefore, the struts were printed parallel to each other.

\subsection{Synthesis of SNAP}

A modified protocol for SNAP synthesis was used in this study [29]. Briefly, $1000 \mathrm{mg}$ of NAP was dissolved in $25 \mathrm{ml}$ of methanol. Next, $15 \mathrm{ml}$ of $1 \mathrm{M} \mathrm{HCl}, 500 \mu \mathrm{l}$ of $\mathrm{H}_{2} \mathrm{SO}_{4}(98 \%)$ and $724.5 \mathrm{mg}$ of $\mathrm{NaNO}_{2}$ were added and mixed, respectively. After 15 min of stirring and $45 \mathrm{~min}$ of ice-cooling, the liquid portion was evaporated under air flow at room temperature. The dark green crystals were rinsed and filtered by ice-cooled deionized water and dried by the freeze-drying procedure. The final green crystals were kept in the darkness at $-20^{\circ} \mathrm{C}$.

\subsection{Characterization of SNAP}

Ten $\mathrm{mM}$ grounded SNAP was dispersed in deionized water and the ultraviolet-visible (UV-Vis) spectra were recorded in the 
wavelength range of 200-700 nm using a UV-Vis spectrophotometer (Lambda 25, Perkin Elmer, Singapore). The SNAP crystal morphology was inspected under polarized optical microscopy (Olympus, Japan).

\subsection{Preparation of NO-releasing and control coatings}

By doping the SNAP molecules into polymeric matrices, the crystal form of SNAP with strong intermolecular interactions will be formed which result in slow dissolution and NO release $[30,31]$. In a previous study, we compared PEG, PCL and PEG-PCL as SNAP reservoirs and concentrations of 5, 10, 15 and $20 \mathrm{wt} \%$ SNAP. The results displayed that PEG-PCL (1:1) with 10\% SNAP covered with a PCL topcoat $(\mathrm{tc})$ layer is the optimum polymeric matrix to release NO for 14 days in the physiological range [32]. According to our previous results, the coating solution to create a SNAP reservoir layer was prepared by dissolving $50 \mathrm{mg}$ PEG and $50 \mathrm{mg}$ PCL in $1 \mathrm{ml}$ THF. This solution was used for coating of control samples. For NO-releasing grafts, $10 \mathrm{wt} \%$ SNAP was also added to the coating solution. Two hundred $\mu \mathrm{l}$ of donor-storing solution was injected inside each rotating graft in 2 steps in darkness. After solvent evaporation at room temperature, the SNAP containing coating layer was dip-coated in PCL solution prepared by dissolving $100 \mathrm{mg}$ PCL in $1 \mathrm{ml}$ THF to create the topcoat layer. This top-coat layer was created to cover the main coating and to control the release kinetics. The final grafts (Fig. 1c) were freeze-dried and kept at $-20{ }^{\circ} \mathrm{C}$.

\subsection{Morphological evaluation of SDVGs}

The coated grafts were loaded on supporting stubs covered with adhesive carbon stickers and sputter coated with a thin layer of gold $(\mathrm{Au})$ (Fisons Instruments, UK). The morphology of specimens was observed using a scanning electron microscope (Streoscan S360, Leica Cambridge, UK) at the acceleration voltage of $20 \mathrm{KV}$.

\subsection{NO release measurement}

The prepared UV-sterilized grafts with $1 \mathrm{~cm}$ length were immersed in $10 \mathrm{ml}$ PBS as releasing medium and incubated at $37{ }^{\circ} \mathrm{C}$ in darkness $(\mathrm{n}=6)$. At pre-determined time-points, $150 \mu \mathrm{l}$ samples were collected for NO-measurement. The amount of NO was measured using a modified Griess assay [14,33,34]. Briefly, $50 \mu \mathrm{l}$ sample and $50 \mu \mathrm{l}$ of $1: 1$ mixture of $2 \mathrm{~g}$ sulfanilamide in $100 \mathrm{ml}$ deionized water with $3.44 \mathrm{ml} \mathrm{H}_{3} \mathrm{PO}_{4}$ (85\%) and $0.2 \mathrm{~g}$ NEDD in $100 \mathrm{ml}$ deionized water were loaded in 96-well ELISA plate and incubated at room temperature for 15 min under gentle shaking. Next, due to the inability of the Griess assay to detect the nitrate amount [35], nitrate content was reduced to nitrite by transferring $50 \mu \mathrm{l}$ of the $\mathrm{VCl}_{3}$ solution, prepared by dissolving $400 \mathrm{mg} \mathrm{VCl}_{3}$ in $50 \mathrm{ml} 1 \mathrm{M} \mathrm{HCl}$ and $60 \mathrm{~min}$ incubation at $60^{\circ} \mathrm{C}$ to be detectable by Griess reaction. Subsequently, the plate was cooled down at ambient temperature and the absorbance was measured at $550 \mathrm{~nm}$. The NO concentration was calculated using standard curves generated from serially diluted $\mathrm{NaNO}_{2}$ solutions.

\subsection{Leachate collection from SDVGs}

To obtain the extract from the grafts, $10 \mathrm{mg}$ of NO-releasing or control grafts were incubated in $10 \mathrm{ml}$ of DMEM medium at $37^{\circ} \mathrm{C}$ according to ISO 10993-5:2009 test [19,20,36]. After $24 \mathrm{~h}$, the grafts were removed from the solution and kept in the fridge. Ten $\%$ FBS and $1 \%$ penicillin-streptomycin solution were freshly added to the leachates before experiments $[19,20,36]$.

\subsection{Cell culture}

HUVECs were cultured in DMEM supplemented with 10\% FBS with $1 \%$ penicillin-streptomycin antibiotic solution in humidified air containing $5 \% \mathrm{CO}_{2}$ at $37^{\circ} \mathrm{C}$.

\subsection{Morphological study of HUVECs}

A confluence monolayer of HUVECs was detached from T-75 flask using trypsin and viable cells were counted by trypan blue staining. To assess the effects of leachates from NO-releasing and control grafts on HUVECs morphology and proliferation, cells were diluted in leachates and $10^{4}$ cells/well were seeded in 96-well plate $(n=3)$ and incubated at $37^{\circ} \mathrm{C}$. After $24 \mathrm{~h}$, the morphology of cells was inspected by an inverted microscope (Olympus, Japan) and images were captured for further analysis. Carbon dot staining was also performed to further analyze the morphology of cells using a fluorescent microscope (Olympus, Japan).

\subsection{Cell migration assay}

The migration rate of ECs from adjacent healthy endothelium is crucial for successful endothelialization of vascular implant. The scratch assay was used to investigate the effect of NO-releasing and control grafts on EC migration rate. HUVECs were seeded in 96-well plates $(n=3)$ at a density of $10^{4}$ cells/well and incubated at $37^{\circ} \mathrm{C}$ to obtain a confluent monolayer. A vertical scratch wound was created with a $100-\mu \mathrm{L}$ pipette tip and the culture media was aspirated and cells were rinsed with PBS to remove detached cells. Since the migration of cells from the adjacent vessels is critical for endothelialization, the scratch line is a cell-free zone which can mimic the graft's edges after implantation. The wounded monolayers were incubated with leachate of NO-releasing grafts, control grafts, or fresh culture media (positive control) for $24 \mathrm{~h}$ at $37^{\circ} \mathrm{C}$. Inverted microscope (Olympus, Japan) was used to monitor the cell migration at $0 \mathrm{~h}$ and $24 \mathrm{~h}$ after scarification.

\subsection{Cytocompatibility assay}

To assess cell viability in presence of leachates, MTT colorimetric assay was carried out on day 1 and 3 after cell seeding. Hundred $\mu \mathrm{l}$ of HUVEC suspension $\left(5 \times 10^{3}\right.$ cells/well) in leachates supplemented with $10 \%$ FBS were seeded in 96 -well plates and incubated at $37{ }^{\circ} \mathrm{C}$ and $5 \% \mathrm{CO}_{2}$. At each time point, the medium was aspirated and $110 \mu \mathrm{l}$ of $5 \mathrm{mg} / \mathrm{ml}$ 3-(4,5-dimethylthiazol-2-yl)-2,5-diphenylte trazolium bromide in PBS was added to each well $(n=6)$. After $4 \mathrm{~h}$ incubation at $37{ }^{\circ} \mathrm{C}$ and $5 \% \mathrm{CO}_{2}$ in darkness, the supernatant was replaced with $110 \mu \mathrm{l}$ of DMSO and shaked for $15 \mathrm{~min}$ to dissolve the formazan crystals produced by viable cells. Hundred $\mu$ l of the supernatant was transferred to a new 96-well plate and the absorbance was measured at $570 \mathrm{~nm}$ by using a microplate reader (BioTek, USA) [37,38].

\subsection{Angiogenesis and biocompatibility assessment in-vivo}

In order to determine the effect of produced SDVGs on angiogenesis and cytotoxicity in-vivo, the CAM assay has been carried out. Briefly, fertilized eggs at embryonic day 1 (ED1) were purchased from a local company and incubated at $37^{\circ} \mathrm{C}$ in a $60 \%$ humidified atmosphere and rotated twice a day. On ED3, $1.5 \mathrm{ml}$ of albumen was aspirated with a syringe to enhance an empty space under the eggshell and the shell's hole created by the needle was covered with tape and incubated at the same environment. On ED8, an approximate $1 \mathrm{~cm}^{2}$ square shape window was created with a sharp blade under sterile conditions and the shell fragment was removed to access the CAM beneath. The UV-sterilized grafts with 
$2.5 \mathrm{~mm}$ length were randomly distributed $(\mathrm{n}=3)$ and gently placed on the CAM. The eggshell fragment was put back on the window and sealed with a sterile tape. The eggs were further incubated horizontally in the same environment without rotation. After $72 \mathrm{~h}$ of incubation, the window was opened and the CAM was inspected and the images and videos were captured by a camera $[38,39]$. The images were quantitatively analyzed using WimCAM online software and the vascular junctions were counted in rectangular equally sized frames.

\subsection{In-vitro antimicrobial evaluation}

The antibacterial activity of NO-releasing and control grafts was tested against both Gram-positive (S. aureus, ATCC 8325-4) and Gram-negative (E. coli, ATCC 25922) bacteria using a disc diffusion assay. The 3d-printed discs with $200 \mu \mathrm{m}$ thickness and $5 \mathrm{~mm}$ diameter were prepared and coated with NO-releasing or control coating. E. coli and $S$. aureus solutions were prepared at a concentration of $10^{5} \mathrm{CFU} \cdot \mathrm{ml}^{-1}$ and were homogeneously streaked on LB and TSB agar plates $(n=3)$, respectively [40-42]. After inoculation, the UV-sterilized discs were loaded on the plates and incubated at $37^{\circ} \mathrm{C}$. After $24 \mathrm{~h}$, the inhibition zones were inspected and recorded with a camera.

Moreover, the viability of strains after incubation with the NOreleasing and control specimens was also investigated by the CFU counting method. Briefly, $10^{7} \mathrm{CFU} \cdot \mathrm{ml}^{-1}$ of $S$. aureus and E. coli inoculum were prepared in PBS $+10 \%$ culture medium [32] (TSB and LB, respectively). The NO-releasing and control specimens were incubated in $2 \mathrm{ml}$ of bacterial solutions with $200 \mathrm{rpm}$ shaking at $37^{\circ} \mathrm{C}$. After $24 \mathrm{~h}, 100 \mu \mathrm{l}$ of the bacterial solution were collected from each tube and plated on blood agar and LB agar for CFU counting.

\subsection{Statistical analysis}

All data were expressed as mean \pm standard deviation (SD). One-way or two-way analysis of variance (ANOVA) was performed for statistical analysis and followed by Tukey or Bonferroni posttests, respectively. $\mathrm{P}<0.05$ was considered significant.

\section{Results and discussion}

\subsection{3d-printed and coated SDVGs}

Considering the advantages of 3d-printing technology for preparation of patient-specific implants, the FDM 3d-printer was used in the current study to fabricate SDVGs. In an earlier research, we investigated the effect of printing parameters on creating the vascular grafts with homogeneous morphology from PLA filament using a FDM printer [25]. In the current work, the luminal surface of 3d-printed SDVGs (Fig. 1a) was modified with NO-releasing coating (Fig. 1c) to improve the bactericidal properties and the healing process of implants in-vivo. The PEG, as a hydrophilic polymer to absorb water and facilitate the SNAP dissolution $[43,44]$, and PCL, as a hydrophobic polymer with slow degradation $[45,46]$, were blended to prepare the donor-storing coating. It has been shown that the addition of PEG to the PCL solution can decrease the interfacial tension of the solution which consequently enhances the shrinkage of the coating after the solvent evaporation and subsequently a porous microstructure will be formed $[47,32]$. The obtained porous structure is beneficial to enhance the water uptake and improve the NO flux compared to NO release by PCL erosion from pure PCL matrix. Based on the result of our previous study that indicated the PEG-PCL-SNAP with PCL topcoat (tc) as an optimum SNAP reservoir to release NO in the physiological range for 14 days [32], the PEG-PCL-SNAP-tc was chosen in this study for further evaluation.

Representative morphological features of 3d-printed grafts and same grafts with NO-releasing layer covered by PCL topcoat are given in Fig. 1. It is evident from the figure that 3d-printed grafts were created from smooth circular struts with uniform orientation and morphology (Fig. 1b). After top-coating, the morphology was changed to be rougher but the location of struts is still visible (Fig. 1d).

\subsection{SNAP characterization}

Fig. 2a shows the UV-Vis spectra of $10 \mathrm{mM}$ synthesized SNAP in deionized water. The appearance of characteristic absorbance maxima at 340 and $590 \mathrm{~nm}$ illustrated the presence of S-NO bond in synthesized SNAP $[48,18,48]$. The representative absorbance of SNAP crystals indicated the purity of the synthesized donor without any extra peaks related to impurities. Fig. $2 \mathrm{~b}$ represents the morphology of SNAP crystals on a glass slide evaluated by polarized optical microscopy.

\subsection{NO release profile}

It has been reported that a hydrophobic top-coat layer covering the SNAP-reservoir coating can optimize the NO-release kinetics $[49,50]$. In this study, the PCL top-coat was used to control the NO-release profile. In order to evaluate the NO-release profile, the prepared grafts were soaked in PBS at $37^{\circ} \mathrm{C}$ and the SNAP diffusion into PBS was monitored on different time points. On the first day of soaking, an initial burst release was detected which can be helpful for the success of SDVG during the "decisive period" of implantation. After passing the "decisive period", from the second day of implantation the grafts needed to release NO in the physiological range $\left(0.5-4 \times 10^{-10} \mathrm{~mol} \cdot \mathrm{cm}^{-2} \cdot \mathrm{min}^{-1}\right)[10,49]$ of NO which continuously secreted from ECs. Fig. 3 shows the controlled NOrelease behavior of SDVGs over 14 days. From day 2 onward, the NO-release was in the physiologic range which is shown in the green zone.

It should be mentioned that the NO flux was measured after UV sterilization. It has been shown that UV irradiation cannot alter the chemical structure of PCL [50], which covered the outer surface of the prepared grafts. In addition, approximately $99 \%$ of the SNAP active content was retained in the coating after UV irradiation for $1.5 \mathrm{~h}[18]$.

\subsection{Proliferation, morphology and migration of ECs}

Endothelium regeneration of the luminal surface is a crucial factor in the clinical success of SDVGs especially while the NO flux decreases after a couple of weeks. After implantation of SDVGs, the ECs migrate from the adjacent vessel and grow from the cut edges towards the center of the lumen to form a complete monolayer [51]. In the endothelialization process, the EC motility and migration speed would be critical for tissue healing.

It has been shown that one of the physiological roles of NO is to stimulate EC proliferation [16,22]. As a proof of concept, the proliferation and morphology of HUVECs after $24 \mathrm{~h}$ was inspected by optical and fluorescent microscopy. Fig. 4 represents the phase contrast and fluorescent images of HUVECs after $24 \mathrm{~h}$ incubation with different leachate media. Cell proliferation was clearly higher in presence of NO which agreed with the results of previous studies $[15,16]$. Although in the NO-releasing condition, the cells grow more confluent whereas in both conditions, cells represent the spread out (elongated) morphology displaying an appropriate environment for cell growth. This cellular elongation is required for angiogenesis and network formation [52]. These results indi- 

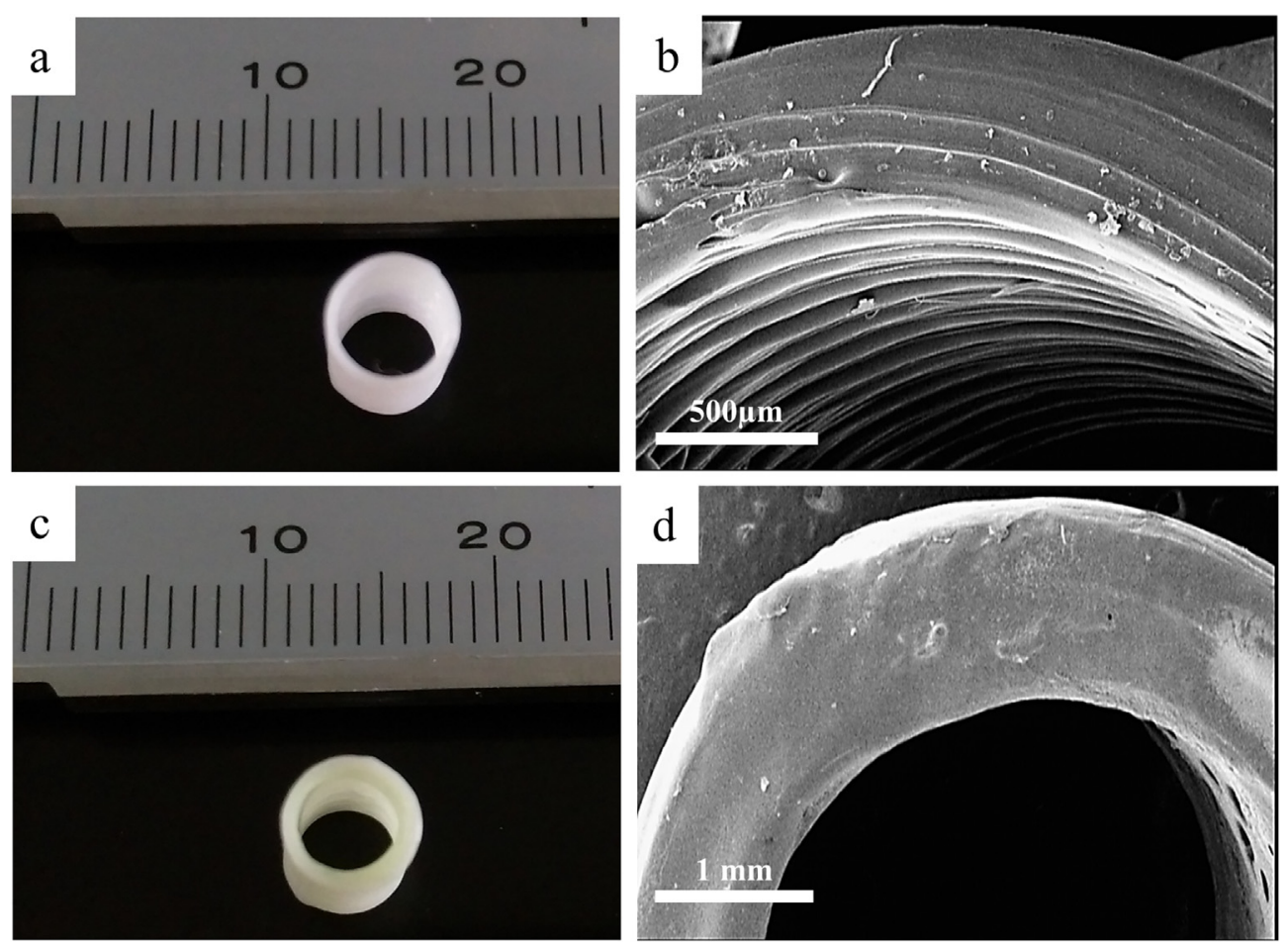

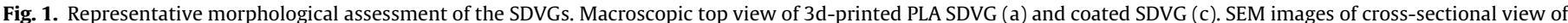
pristine SGVG (b) and coated SDVG (d).
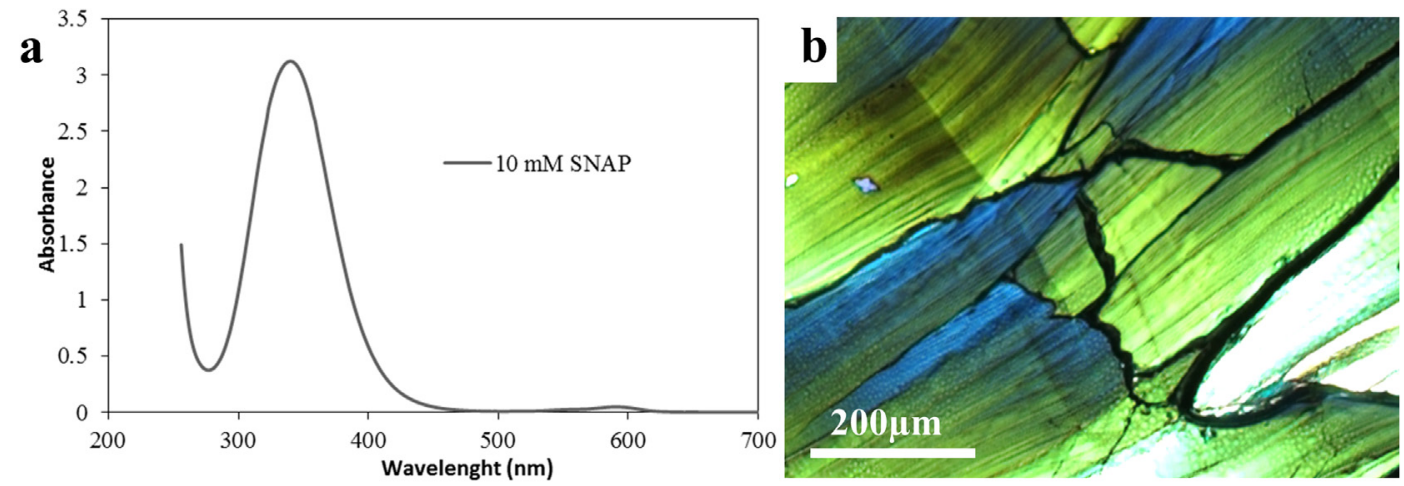

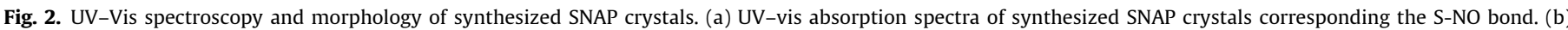
Microscopic view of SNAP crystals under polarized light.

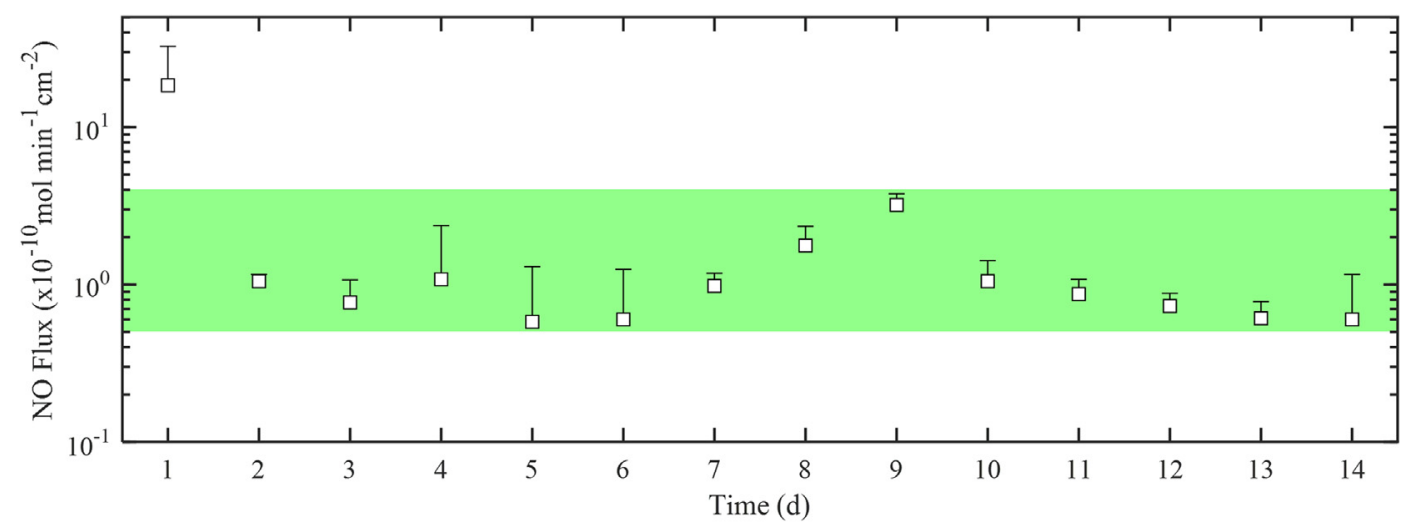

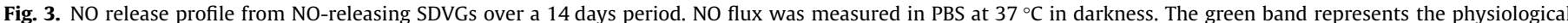

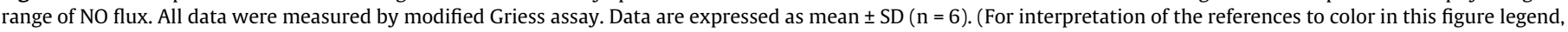
the reader is referred to the web version of this article.) 

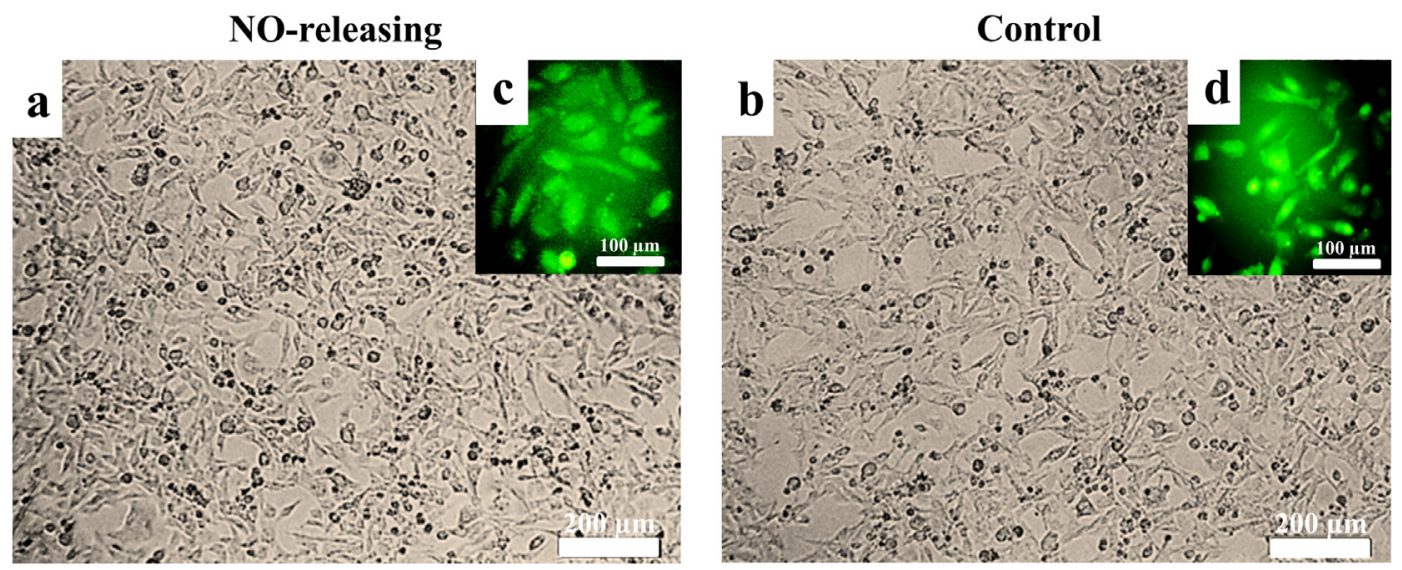

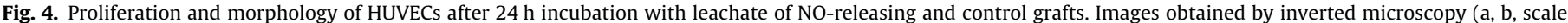
bar: $200 \mu \mathrm{m}$ ) and fluorescence microscopy (c, d, scale bar: $100 \mu \mathrm{m}$ ).

cate that NO-releasing 3d-printed SDVGs can promote proliferation of ECs and consequently accelerate endothelial regeneration in-vivo.

ECs play a key role in the wound healing process of vascular grafts [54,55]. The migration rate of ECs towards the wounded site of implantation is an important factor which can accelerate the healing process after surgery. As a consequence, an accelerated regeneration of the endothelium monolayer after implantation could reduce the risk of bacterial infection and thrombosis. Yang et al. reported that the NO release accelerated HUVEC proliferation and migration [16]. It has been shown that exogenous NO donor can up-regulate the expression of cytoskeletal proteins in ECs which are critical for elongation of actin filaments, known as VASP, and consequently improve the migration [13].

Fig. $5 \mathrm{a}$ shows the migration of ECs after $24 \mathrm{~h}$ incubation in presence of different leachates or culture medium. The obtained images

$\mathbf{a}$

Oh
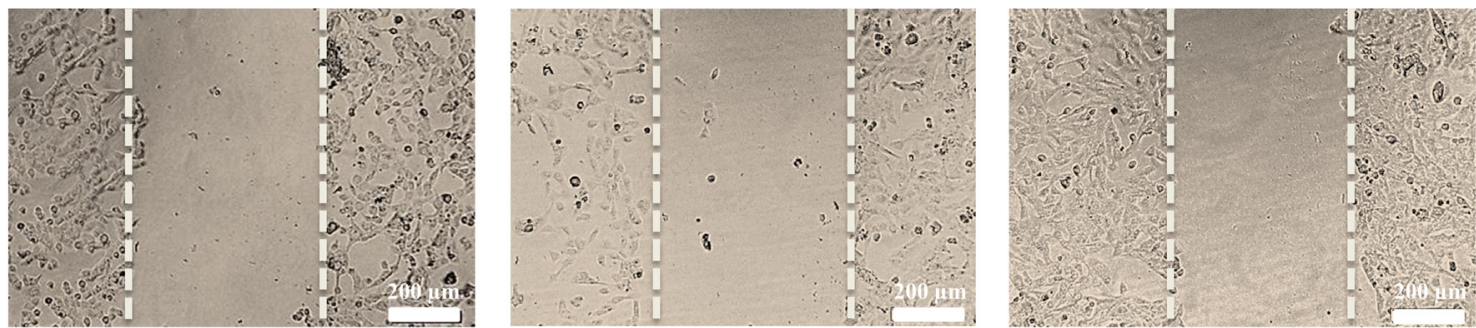

$24 h$
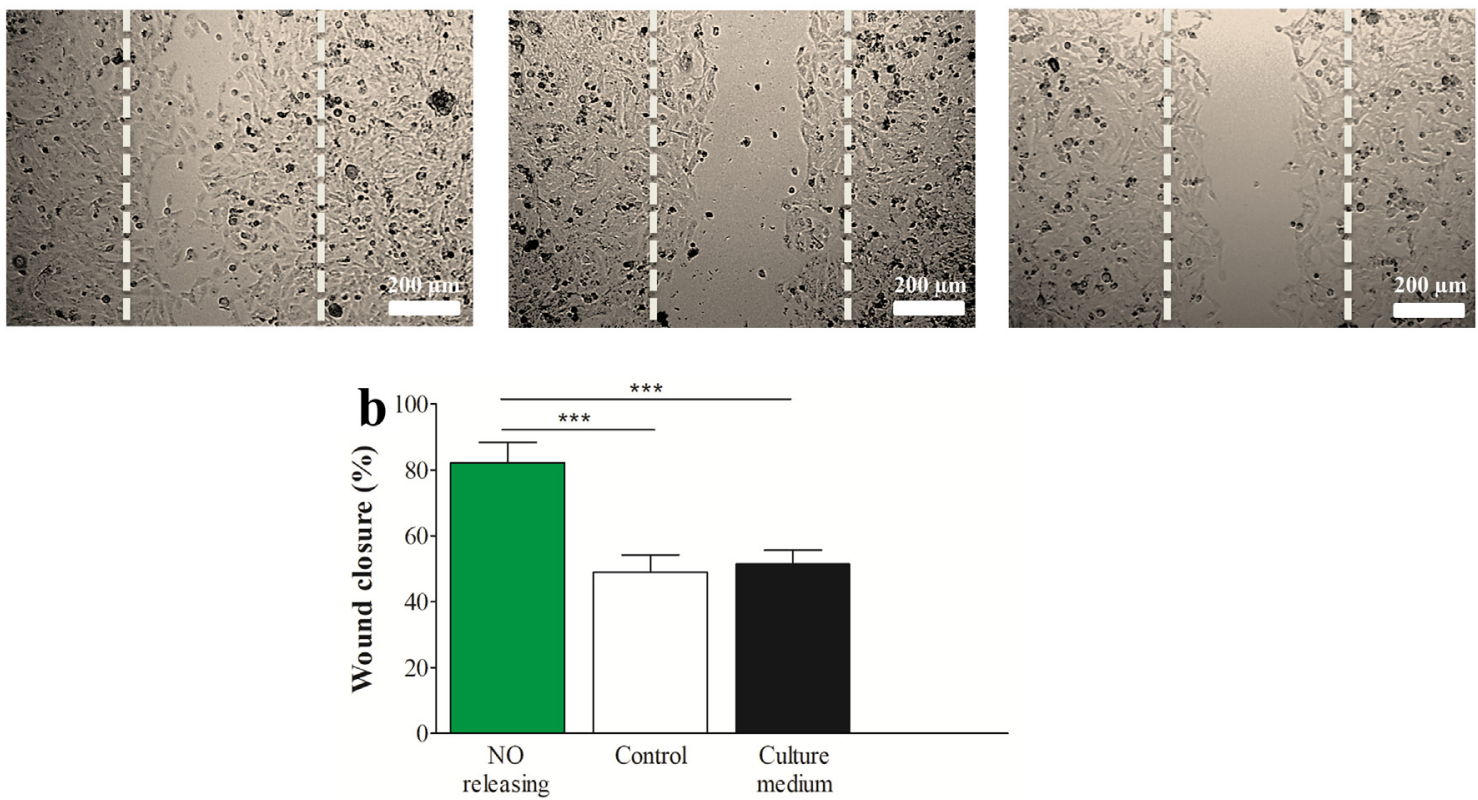

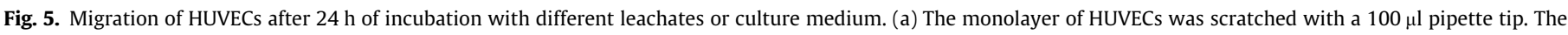

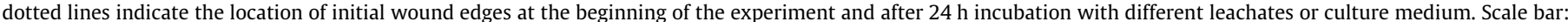

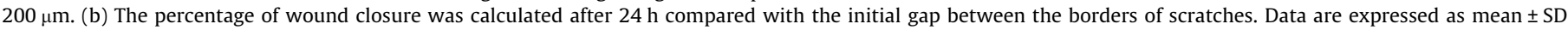
$(\mathrm{n}=3)$. 
were quantitatively analyzed with the WimScratch online software program. The results demonstrate that NO-releasing significantly enhanced the migration rate of ECs and that after $24 \mathrm{~h}$ the wounded area in presence of NO was decreased by $42 \%$ compared to control and positive control (culture medium) (Fig. 5b). However, for the control grafts and positive control, cells showed no difference in migration speed. This confirms the accelerating effect of NO on the EC migration rate, which would be promising for faster wound closure after implantation.

This finding is in agreement with the previous studies on NOreleasing stents $[16,22]$ that reported significant enhancement of HUVEC's proliferation and migration by NO donor supplementation in the culture medium. Their in-vivo results also demonstrated that NO-releasing stents promote re-endothelialization and reduce the chance of re-stenosis [16]. The present study advances and takes our prior work into the next level by examining the EC migration and proliferation to investigate the healing process of SDVGs in-vitro.

The endothelial regeneration on the lumen of synthetic vascular grafts without NO-releasing is limited in-vivo which consequently increases the thrombogenicity and risk of contamination [56-58]. The results of the current study demonstrate the promotion of endothelialization in response to NO release, which acts as an anti-coagulating layer with bactericidal properties and can promisingly increase the success rate of implantation.

\subsection{Cytocompatibility assessment}

Treatment of cells with biomaterials and chemical agents can alter cell viability and metabolism and it is necessary to evaluate the cytotoxicity of new products. In order to assess the cytotoxicity of NO-releasing and control grafts, MTT assay was performed. The findings summarized in Fig. 6 illustrate the non-cytotoxic effect of manufactured grafts both in a short-term $(24 \mathrm{~h})$ and long-term $(72 \mathrm{~h})$ period. This finding is in line with previous study results which also reported zero toxicity of leachate from films with $10 \mathrm{wt} \%$ SNAP $[18,19,59,20]$. Moreover, the results revealed that EC proliferation rate was significantly higher after $24 \mathrm{~h}$ incubation with NO-releasing graft's leachate compared to the control group. After $72 \mathrm{~h}$, the propagation of ECs was also significantly higher than after $24 \mathrm{~h}$ in which demonstrates the support of cell growth in the presence of leachates, although the difference of NOreleasing and control group was not statistically significant at $72 \mathrm{~h}$. Our results are consistent with earlier reports of biocompat-

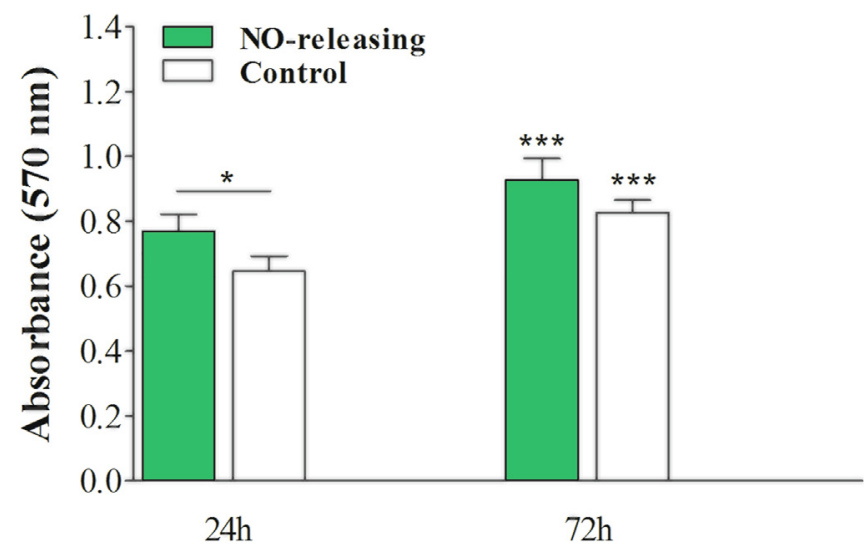

Fig. 6. Cytocompatibility evaluation of grafts. EC viability measured by MTT assay after $24 \mathrm{~h}$ and $72 \mathrm{~h}$ of incubation with leachates of NO-releasing and control grafts. The proliferation rate was significantly higher $(\mathrm{P}<0.05)$ in the NO-releasing group $(n=6)$ compared to the control group $(n=6)$ after $24 \mathrm{~h}$. The growth rate was also significantly higher $(\mathrm{P}<0.001)$ after $72 \mathrm{~h}$ which illustrates the propagation of ECs. Data are expressed as mean \pm SD $(n=6)$. ibility and the higher rate of EC proliferation by NO treatment $[16,20]$.

\subsection{In-vivo angiogenesis and biocompatibility evaluation}

The CAM assay is a cost-effective, minimally invasive, simple and rapid method to evaluate the biocompatibility and angiogenic potential of biomaterials and even used as a bioreactor $[39,60]$. CAM assay is also a standard method used to assess the activity and toxicity of drug delivery systems. The chemicals in the CAM can absorb through the membrane and reach the systemic circulation and therefore affect the development of the embryo [61].

In this study, CAM assay was used to investigate the effect of grafts with or without NO-release on the viability of chick embryo and angiogenesis in-vivo. To the best of our knowledge, this is the first report of 3d-printed vascular graft implantation on the CAM membrane and investigation of the resulting angiogenesis and embryonic viability.

The results (Fig. 7a-b) demonstrate that control grafts were compatible with the CAM model since they did not display any damage to blood vessels or embryo viability. Fig. 7c shows the significant increase in formation of new vascular junctions in the presence of NO-release $(97.66 \pm 7.50)$ compared to the control groups $(73 \pm 9.84)$ after $72 \mathrm{~h}$. The higher rate of angiogenesis from the existing blood vessels in response to NO can further prove the controlled release of NO in the physiological range and the results of our in-vitro EC migration behavior.

Moreover, new capillaries branching were grown on the SDVGs wall, even more concentrated around NO-releasing SDVGs compared to control grafts, which is promising for EC stimulation to migrate to the lumen of the implant.

In the angiogenesis process, ECs locally proliferate in response to an angiogenic stimulus and play a vital role in this process [53]. The angiogenic potential of NO in the CAM assay is in agreement with our results of HUVEC migration rate in-vitro. The present study confirms the angiogenic potential of NO which can be concluded that by using NO-releasing systems, the coverage of ECs could be improved on the lumen of SDVGs implants. The results of this study are in agreement with a previous report of angiogenic potential of Spermine NONOate as an exogenous NO donor [62]. Another study also reported that the local NO release enhanced angiogenesis in-vivo [63]. The enhancement of angiogenesis in response to NO-releasing, both in-vitro and in-vivo, can also illustrate long-term antibacterial properties of grafts as previously described [64,65]. Moreover, this angiogenic activity which is essential for tissue healing $[66,67]$ is promising for tissue regeneration and integration after implantation.

In the movies, the vascular motion at systole and diastole and the movement of the embryo is observable which confirms the viability of the embryo and the biocompatibility of grafts. From the anatomical aspect, the CAM artery and vein were distinguishable by their color. In contrast to the internal circulation, in the extraembryonic circulatory system the arterial blood is deoxygenated and therefore the artery looks darker than the vein [68]. In both control (Supplementary video 1) and NO-releasing (Supplementary video 2 ) groups, as expected, the wall motion of the vein is negligible while the arterial motion was remarkable being in line with earlier reports [68].

\subsection{Antibacterial properties of NO-releasing coating}

NO is a natural molecule with bactericidal properties by damaging the microbial DNA, proteins and lipids [69]. The prolonged NOreleasing in a controlled manner is expected to inhibit bacterial growth on the biomaterial surface. To investigate the antibacterial activity of the NO-releasing coating, the inhibition zone assay was 

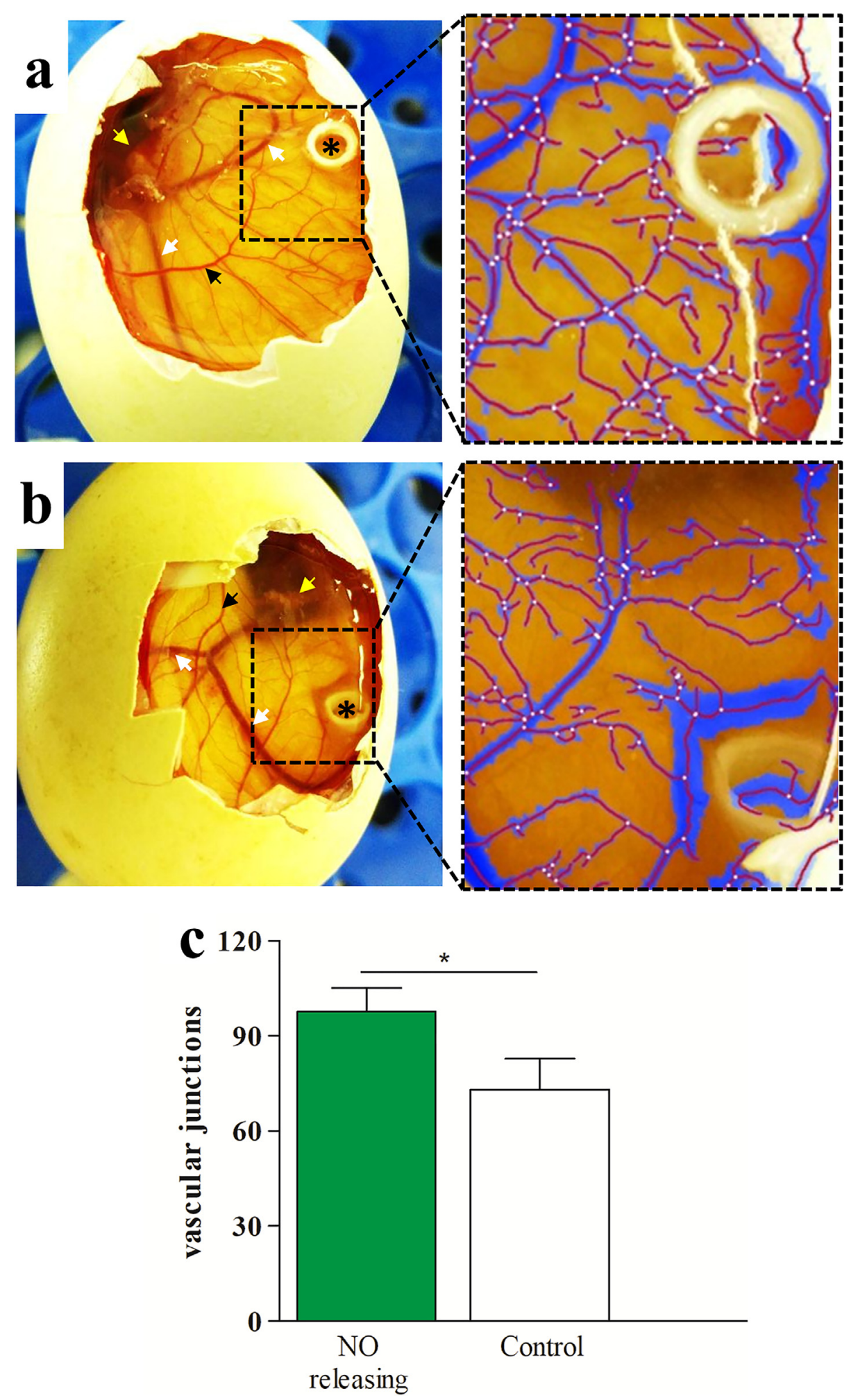

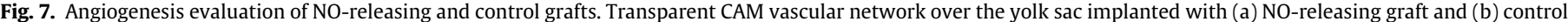

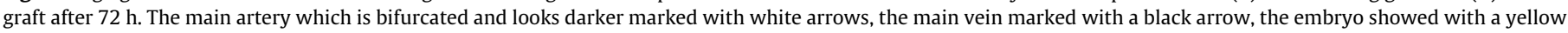

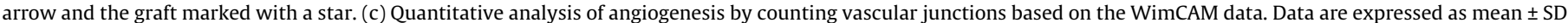
$(n=3)$. (For interpretation of the references to color in this figure legend, the reader is referred to the web version of this article.)

carried out using Gram-positive (S. aureus) and Gram-negative (E. coli) strains. In this method, the inhibition of bacterial growth is directly related to antibacterial properties of the biomaterial. Fig. 8 reveals the inhibition halos of NO-releasing and control coatings on agar plates after $24 \mathrm{~h}$ of incubation at $37^{\circ} \mathrm{C}$. In both strains,
NO-releasing coating inhibited the growth of bacteria with an approximately $13 \mathrm{~mm}$ diameter zone of inhibition. The SNAP-free control grafts did not display any inhibitory zone in both species. The results of the CFU counting method also showed a reduction of $99.99-100 \%$ of microorganisms in presence of NO-releasing 
E. coli

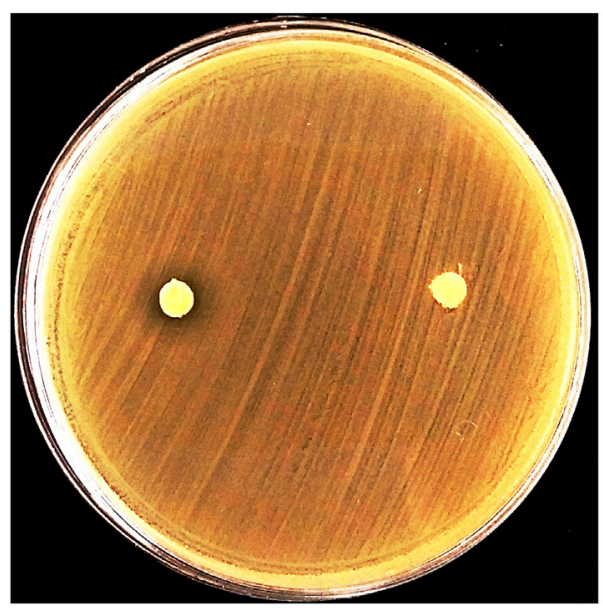

S. aureus

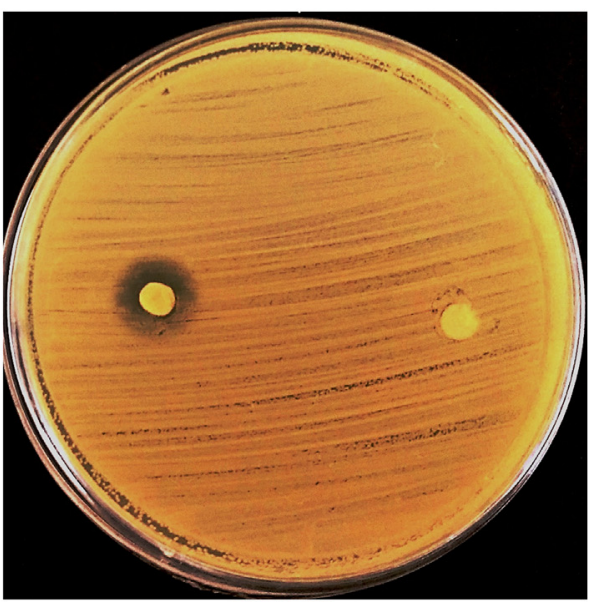

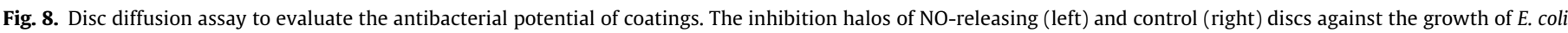
and $S$. aureus strains after $24 \mathrm{~h}$ incubation at $37^{\circ} \mathrm{C}$. Data are expressed as mean $\pm \mathrm{SD}(\mathrm{n}=3)$.

grafts after $24 \mathrm{~h}$ while the bacteria incubated with control grafts proliferated and displayed a steady-state level [32] which was in agreement with inspected inhibition zone halos.

These findings confirm that fabricated NO-releasing SDVGs can significantly reduce the viability of bacteria after implantation. The inhibition of bacterial growth can promisingly reduce the chance of biofilm formation which should further be investigated. The results are in accordance with results of previous studies [40-42,32].

\section{Conclusion}

In this study, a composite NO-releasing coating was developed on 3d-printed vascular grafts. This coating can release NO in a controlled manner which mimics the native endothelium properties. The results showed that NO-releasing grafts enhance the migration rate of ECs which consequently accelerate tissue regeneration at the site of implantation. This faster endothelium recovery is favorable while endogenous NO production is disrupted because of ECs damaged during operation and can result in the success of implantation in terms of inhibition of thrombosis and infection. Moreover, the NO-releasing SDVGs exhibited a remarkable angiogenic potential in-vivo and antibacterial properties against both Gram-positive and Gram-negative species in-vitro. Considering these promising results, NO-releasing 3d-printed SDVGs represent a promising approach to prepare more successful SDVGs with accelerated healing and bactericidal properties.

\section{Declaration of Competing Interest}

There is no conflict of interest to declare.

\section{Appendix A. Supplementary material}

Supplementary data to this article can be found online at https://doi.org/10.1016/j.actbio.2019.05.002.

\section{References}

[1] M. Gimeno, P. Pinczowski, M. Pérez, A. Giorello, M.Á. Martínez, J. Santamaría, M. Arruebo, L. Luján, A controlled antibiotic release system to prevent orthopedic-implant associated infections: an in vitro study, Eur. J. Pharm. Biopharm. 96 (2015) 264-271.

[2] S. Yuran, A. Dolid, M. Reches, Resisting bacteria and attracting cells: spontaneous formation of a bifunctional peptide-based coating by on-surface assembly approach, ACS Biomater. Sci. Eng. 4 (12) (2018) 4051-4061.
[3] M. Rahmati, M. Mozafari, Protein Adsorption on Polymers, Materials Today Communications 17 (2018) 527-540.

[4] J. Kang, B.W. Lee, J.H. Kim, D.G. Yoo, W.-C. Cho, S.W. Kim, S.J. Choo, Granulocyte colony-stimulating factor minimizes negative remodeling of decellularized small diameter vascular graft conduits but not medial degeneration, Ann. Vasc. Surg. 27 (4) (2013) 487-496

[5] L. Xue, H.P. Greisler, Biomaterials in the development and future of vascular grafts, J. Vasc. Surg. 37 (2) (2003) 472-480.

[6] M.B. Elliott, S. Gerecht, Three-dimensional culture of small-diameter vascular grafts, J. Mater. Chem. B 4 (20) (2016) 3443-3453.

[7] M. Peck, D. Gebhart, N. Dusserre, T.N. McAllister, N. L'heureux, The evolution of vascular tissue engineering and current state of the art, Cells Tiss. Organs 195 (1-2) (2012) 144-158.

[8] A. Yazdanpanah, M. Tahmasbi, G. Amoabediny, J. Nourmohammadi, F, Moztarzadeh, M. Mozafari, Fabrication and characterization of electrospun poly-L-lactide/gelatin graded tubular scaffolds: toward a new design for performance enhancement in vascular tissue engineering, Prog. Nat. Sci. Mater. Int. 25 (5) (2015) 405-413.

[9] E.J. Brisbois, J. Bayliss, J. Wu, T.C. Major, C. Xi, S.C. Wang, R.H. Bartlett, H. Handa, M.E. Meyerhoff, Optimized polymeric film-based nitric oxide delivery inhibits bacterial growth in a mouse burn wound model, Acta Biomater. 10 (10) (2014) 4136-4142.

[10] J. Pant, M.J. Goudie, S.P. Hopkins, E.J. Brisbois, H. Handa, Tunable nitric oxide release from S-nitroso-N-acetylpenicillamine via catalytic copper nanoparticles for biomedical applications, ACS Appl. Mater. Interfaces 9 (18) (2017) 15254-15264.

[11] A. Vermote, S. Van, Calenbergh small-molecule potentiators for conventional antibiotics against staphylococcus aureus, ACS Infect. Dis. 3 (11) (2017) 780 796.

[12] Maryam Rahmati, Masoud Mozafari, Nano-Immunoengineering: Opportunities and Challenges, Curr. Opin. Biomed. Eng. 10 (2019) 51-59.

[13] M.S. Segal, R. Shah, A. Afzal, C.M. Perrault, K. Chang, A. Schuler, E. Beem, L.C. Shaw, S.L. Calzi, J.K. Harrison, Nitric oxide cytoskeletal-induced alterations reverse the endothelial progenitor cell migratory defect associated with diabetes, Diabetes 55 (1) (2006) 102-109.

[14] F. Kabirian, G. Amoabediny, N. Haghighipour, N. Salehi-Nik, B. ZandiehDoulabi, Nitric oxide secretion by endothelial cells in response to fluid shear stress, aspirin and temperature, J. Biomed. Mater. Res. Part A 103 (3) (2015) 1231-1237.

[15] J. Gao, Y. Wang, S. Chen, D. Tang, L. Jiang, D. Kong, S. Wang, Electrospun poly- $\varepsilon-$ caprolactone scaffold modified with catalytic nitric oxide generation and heparin for small-diameter vascular graft, RSC Adv. 7 (30) (2017) 18775 18784.

[16] Z. Yang, Y. Yang, K. Xiong, X. Li, P. Qi, Q. Tu, F. Jing, Y. Weng, J. Wang, N. Huang, Nitric oxide producing coating mimicking endothelium function for multifunctional vascular stents, Biomaterials 63 (2015) 80-92.

[17] R. Augustine, Y.B. Dalvi, P. Dan, N. George, D. Helle, R. Varghese, S. Thomas, P. Menu, N. Sandhyarani, Nanoceria can act as the cues for angiogenesis in tissueengineering scaffolds: toward next-generation in situ tissue engineering, ACS Biomater. Sci. Eng. 4 (12) (2018) 4338-4353.

[18] M.J. Goudie, E.J. Brisbois, J. Pant, A. Thompson, J.A. Potkay, H. Handa, Characterization of an S-nitroso-N-acetylpenicillamine-based nitric oxide releasing polymer from a translational perspective, Int. J. Polym. Mater. Polym. Biomater. 65 (15) (2016) 769-778.

[19] J. Pant, M.J. Goudie, S.M. Chaji, B.W. Johnson, H. Handa, Nitric oxide releasing vascular catheters for eradicating bacterial infection, J. Biomed. Mater. Res. Part B 106 (8) (2018) 2849-2857. 
[20] M.J. Goudie, J. Pant, H. Handa, Liquid-infused nitric oxide-releasing (LINORel) silicone for decreased fouling, thrombosis, and infection of medical devices, Sci. Rep. 7 (1) (2017) 13623.

[21] S.P. Hopkins, J. Pant, M.J. Goudie, C. Schmiedt, H. Handa, Achieving long-term biocompatible silicone via covalently immobilized S-nitroso-Nacetylpenicillamine (SNAP) that exhibits 4 months of sustained nitric oxide release, ACS Appl. Mater. Interfaces 10 (32) (2018) 27316-27325.

[22] X. Li, H. Qiu, P. Gao, Y. Yang, Z. Yang, N. Huang, Synergetic coordination and catecholamine chemistry for catalytic generation of nitric oxide on vascular stents, NPG Asia Mater. (2018) 1.

[23] F. Kabirian, M. Mozafari, Decellularized ECM-derived bioinks: Prospect for the future, Methods. (2019), https://doi.org/10.1016/j.Ymeth. 2019.04.019.

[24] M. Touri, F. Kabirian, M. Saadati, S. Ramakrishna, M. Mozafari, Additive manufacturing of biomaterials - the evolution of rapid prototyping, Adv Eng. Mater. (2019) 1800511.

[25] F. Kabirian, B. Ditkowski, A. Zamanian, R. Heying, M. Mozafari, An innovative approach towards 3D-printed scaffolds for the next generation of tissueengineered vascular grafts, Mater Today: Proc. 5 (7) (2018) 15586-15594.

[26] C. Chen, J. Tan, W. Wu, L. Petrini, L. Zhang, Y. Shi, E. Cattarinuzzi, J. Pei, H. Huang, W. Ding, Modeling and experimental studies of coating delamination of biodegradable magnesium alloy cardiovascular stents, ACS Biomater. Sci. Eng. 4 (11) (2018) 3864-3873.

[27] C. Best, R. Strouse, K. Hor, V. Pepper, A. Tipton, J. Kelly, T. Shinoka, C. Breuer, Toward a patient-specific tissue engineered vascular graft, J. Tiss. Eng. 9 (2018). 2041731418764709.

[28] J.G. Ausejo, J. Rydz, M. Musioł, W. Sikorska, M. Sobota, J. Włodarczyk, G Adamus, H. Janeczek, I. Kwiecień, A. Hercog, A comparative study of threedimensional printing directions: the degradation and toxicological profile of a PLA/PHA blend, Polym. Degrad. Stab. 152 (2018) 191-207.

[29] C.W. McCarthy, R.J. Guillory, J. Goldman, M.C. Frost, Transition-metalmediated release of nitric oxide (NO) from S-nitroso-N-acetyl-dpenicillamine (SNAP): potential applications for endogenous release of NO at the surface of stents via corrosion products, ACS Appl. Mater. Interfaces 8 (16) (2016) 10128-10135.

[30] E.J. Brisbois, R.P. Davis, A.M. Jones, T.C. Major, R.H. Bartlett, M.E. Meyerhoff, H. Handa, Reduction in thrombosis and bacterial adhesion with 7 day implantation of S-nitroso-N-acetylpenicillamine (SNAP)-doped Elast-eon E2As catheters in sheep, J. Mater. Chem. B 3 (8) (2015) 1639-1645.

[31] Y. Wo, Z. Li, A. Colletta, J. Wu, C. Xi, A.J. Matzger, E.J. Brisbois, R.H. Bartlett, M.E. Meyerhoff, Study of crystal formation and nitric oxide (NO) release mechanism from S-nitroso-N-acetylpenicillamine (SNAP)-doped CarboSi polymer composites for potential antimicrobial applications, Compos. Part B 121 (2017) 23-33.

[32] F. Kabirian, B. Ditkowski, A. Zamanian, M.F. Hoylaerts, M. Mozafari, R. Heying Controlled NO-release from 3D-printed small-diameter vascular grafts prevents platelet activation and bacterial infectivity, ACS Biomater. Sci. Eng. (2019), https://doi.org/10.1021/acsbiomaterials.9b00220.

[33] K.M. Miranda, M.G. Espey, D.A. Wink, A rapid, simple spectrophotometric method for simultaneous detection of nitrate and nitrite, Nitric Oxide 5 (1) (2001) 62-71.

[34] E. García-Robledo, A. Corzo, S. Papaspyrou, A fast and direct spectrophotometric method for the sequential determination of nitrate and nitrite at low concentrations in small volumes, Mar. Chem. 162 (2014) 30-36

[35] K.R. Kunduru, A. Basu, T. Tsah, A.J. Domb, Polymer with pendant diazocoupling functionality for colorimetric detection of nitrates, Sens. Actuat. B 251 (2017) 21-26.

[36] B.M. Grommersch, J. Pant, S.P. Hopkins, M.J. Goudie, H. Handa, Biotemplated synthesis and characterization of mesoporous nitric oxide-releasing diatomaceous earth silica particles, ACS Appl. Mater. Interfaces 10 (3) (2018) 2291-2301.

[37] M. Zamani, M. Khafaji, M. Naji, M. Vossoughi, I. Alemzadeh, N. Haghighipour, A biomimetic heparinized composite silk-based vascular scaffold with sustained antithrombogenicity, Sci. Rep. 7 (1) (2017) 4455

[38] M. Su, J. Huang, S. Liu, Y. Xiao, X. Qin, J. Liu, C. Pi, T. Luo, J. Li, X. Chen, The antiangiogenic effect and novel mechanisms of action of Combretastatin A-4, Sci. Rep. 6 (2016) 28139.

[39] I. Moreno-Jiménez, G. Hulsart-Billstrom, S.A. Lanham, A.A. Janeczek, N Kontouli, J.M. Kanczler, N.D. Evans, R.O. Oreffo, The chorioallantoic membrane (CAM) assay for the study of human bone regeneration: a refinement animal model for tissue engineering, Sci. Rep. 6 (2016) 32168.

[40] W.H. Lee, H. Ren, J. Wu, O. Novak, R.B. Brown, C. Xi, M.E. Meyerhoff, Electrochemically modulated nitric oxide release from flexible silicone rubber patch: antimicrobial activity for potential wound healing applications, ACS Biomater. Sci. Eng. 2 (9) (2016) 1432-1435.

[41] J. Pant, J. Gao, M.J. Goudie, S.P. Hopkins, J. Locklin, H. Handa, A multi-defense strategy: enhancing bactericidal activity of a medical grade polymer with a nitric oxide donor and surface-immobilized quaternary ammonium compound, Acta Biomater. 58 (2017) 421-431.

[42] T.T.H. Thi, Y. Lee, P. Le Thi, K.D. Park, Nitric oxide-releasing injectable hydrogels with high antibacterial activity through in situ formation of peroxynitrite, Acta Biomater. 67 (2018) 66-78.

[43] Y. Wo, E.J. Brisbois, R.H. Bartlett, M.E. Meyerhoff, Recent advances in thromboresistant and antimicrobial polymers for biomedical applications: just say yes to nitric oxide (NO), Biomater. Sci. 4 (8) (2016) 1161-1183.
[44] K.M. Hansson, S. Tosatti, J. Isaksson, J. Wetterö, M. Textor, T.L. Lindahl, P. Tengvall, Whole blood coagulation on protein adsorption-resistant PEG and peptide functionalised PEG-coated titanium surfaces, Biomaterials 26 (8) (2005) 861-872.

[45] A. Repanas, W.F. Wolkers, O. Gryshkov, P. Kalozoumis, M. Mueller, H. Zernetsch, S. Korossis, B. Glasmacher, Coaxial electrospinning as a process to engineer biodegradable polymeric scaffolds as drug delivery systems for antiinflammatory and anti-thrombotic pharmaceutical agents, 2015.

[46] D. Mondal, M. Griffith, S.S. Venkatraman, Polycaprolactone-based biomaterials for tissue engineering and drug delivery: current scenario and challenges, Int. J. Polym. Mater. Polym. Biomater. 65 (5) (2016) 255-265.

[47] Y. Jiang, K. Mao, X. Cai, S. Lai, X. Chen, Poly (ethyl glycol) assisting water sorption enhancement of poly ( $\varepsilon$-caprolactone) blend for drug delivery, J. Appl. Polym. Sci. 122 (4) (2011) 2309-2316.

[48] Y. Li, P.I. Lee, Controlled nitric oxide delivery platform based on S-nitrosothiol conjugated interpolymer complexes for diabetic wound healing, Mol. Pharm. 7 (1) (2010) 254-266.

[49] Y. Wo, Z. Li, E.J. Brisbois, A. Colletta, J. Wu, T.C. Major, C. Xi, R.H. Bartlett, A.J. Matzger, M.E. Meyerhoff, Origin of long-term storage stability and nitric oxide release behavior of CarboSil polymer doped with S-nitroso-N-acetyl-Dpenicillamine, ACS Appl. Mater. Interfaces 7 (40) (2015) 22218-22227.

[50] E.J. Brisbois, H. Handa, T.C. Major, R.H. Bartlett, M.E. Meyerhoff, Long-term nitric oxide release and elevated temperature stability with S-nitroso-Nacetylpenicillamine (SNAP)-doped Elast-eon E2As polymer, Biomaterials 34 (28) (2013) 6957-6966.

[51] M. Gao, H. Zhang, W. Dong, J. Bai, B. Gao, D. Xia, B. Feng, M. Chen, X. He, M. Yin, Tissue-engineered trachea from a 3D-printed scaffold enhances wholesegment tracheal repair, Sci. Rep. 7 (1) (2017) 5246.

[52] A.J. Melchiorri, N. Hibino, J.P. Fisher, Strategies and techniques to enhance the in situ endothelialization of small-diameter biodegradable polymeric vascular grafts, Tiss. Eng. Part B 19 (4) (2013) 292-307.

[53] R. Winter, P. Dungel, F.M.J. Reischies, S. Rohringer, P. Slezak, C. Smolle, S. Spendel, L.-P. Kamolz, N. Ghaffari-Tabrizi-Wizsy, K. Schicho, Photobiomodulation (PBM) promotes angiogenesis in-vitro and in chick embryo chorioallantoic membrane model, Sci. Rep. 8 (1) (2018) 17080.

[54] S. Rohringer, W. Holnthoner, S. Chaudary, P. Slezak, E. Priglinger, M. Strassl, K. Pill, S. Mühleder, H. Redl, P. Dungel, The impact of wavelengths of LED lighttherapy on endothelial cells, Sci. Rep. 7 (1) (2017) 10700.

[55] B.R. Rao, R. Kotcherlakota, S.K. Nethi, N. Puvvada, B. Sreedhar, A. Chaudhuri, C. R. Patra, Ag2 [Fe (CN) 5NO] Nanoparticles Exhibit Antibacterial Activity and Wound Healing Properties, ACS Biomater. Sci. Eng. 4 (9) (2018) 3434-3449.

[56] A.W. Clowes, T. Kohler, Graft endothelialization: the role of angiogenic mechanisms, J. Vasc. Surg. 13 (5) (1991) 734-736.

[57] M. Neufurth, X. Wang, E. Tolba, B. Dorweiler, H.C. Schröder, T. Link, B. DiehlSeifert, W.E. Müller, Modular small diameter vascular grafts with bioactive functionalities 7, Plos one 10 (2015) e0133632.

[58] Y. Pan, X. Zhou, Y. Wei, Q. Zhang, T. Wang, M. Zhu, W. Li, R. Huang, R. Liu, J. Chen, Small-diameter hybrid vascular grafts composed of polycaprolactone and polydioxanone fibers, Sci. Rep. 7 (1) (2017) 3615.

[70] J. Pant, J. Sundaram, M.J. Goudie, D.T. Nguyen, H. Handa, Antibacterial 3D bone scaffolds for tissue engineering application, J. Biomed. Mater. Res. Part B 107 (4) (2018) 1068-1078.

[60] E. Shoba, R. Lakra, M.S. Kiran, P.S. Korrapati, Fabrication of core-shell nanofibers for controlled delivery of bromelain and salvianolic acid B for skin regeneration in wound therapeutics, Biomed. Mater. 12 (3) (2017) 035005.

[61] D. Ribatti, The chick embryo chorioallantoic membrane (CAM) assay, Reprod. Toxicol. 70 (2017) 97-101.

[62] S. Majumder, S. Sinha, J.H. Siamwala, A. Muley, H.R. Seerapu, G.K. Kolluru, V. Veeriah, S. Nagarajan, S.R.C. Sridhara, M.K. Priya, A comparative study of NONOate based NO donors: spermine NONOate is the best suited NO donor for angiogenesis, Nitric Oxide 36 (2014) 76-86.

[63] M. Champeau, V. Póvoa, L. Militão, F.M. Cabrini, G.F. Picheth, F. Meneau, C.P. Jara, E.P. de Araujo, M.G. de Oliveira, Supramolecular poly (acrylic acid)/F127 hydrogel with hydration-controlled nitric oxide release for enhancing wound healing, Acta Biomater. 74 (2018) 312-325.

[64] S. Sato, Y. Nitta, Y. Saiki, S. Kawamoto, A. Iguchi, M. Kaku, Y. Tabata, K. Tabayashi, Enhanced perigraft angiogenesis prevents prosthetic graft infection, Ann. Thorac. Surg. 86 (4) (2008) 1278-1284.

[65] T. Fujii, Y. Watanabe, Multidisciplinary treatment approach for prosthetic vascular graft infection in the thoracic aortic area, J. Thorac. Cardiovasc. Surg. (2015). ra., pp. 15-00187.

[66] C.O. Cassell, O.S. Hofer, W.A. Morrison, K.R. Knight, Vascularisation of tissueengineered grafts: the regulation of angiogenesis in reconstructive surgery and in disease states, Br. J. Plast. Surg. 55 (8) (2002) 603-610.

[67] L.A. DiPietro, Angiogenesis and wound repair: when enough is enough, J. Leukocyte Biol. 100 (5) (2016) 979-984.

[68] K.H. Nam, J. Kim, G. Ra, C.H. Lee, D.G. Paeng, Feasibility study of ex ovo chick chorioallantoic artery model for investigating pulsatile variation of arterial geometry, Plos one 10 (12) (2015) e0145969.

[69] F.C. Fang, Perspectives series: host/pathogen interactions. Mechanisms of nitric oxide-related antimicrobial activity, J. Clin. Invest. 99 (12) (1997) 28182825. 